\title{
Editorial
}

\section{Migraine and Mood Disorders: Prevalence, Clinical Correlations, and Disability}

Migraine is common than expected, with an estimated lifetime prevalence of $7 \%-17 \%{ }^{[1]}$ and is up to four times more common in women than men. ${ }^{[1]}$ Population-based studies have shown association between various psychiatric conditions and migraine. These include major depression, bipolar disorder, panic disorder, phobia, substance dependence, and risk of suicide. ${ }^{[2]}$ Recognizing psychiatric comorbidities in patients with migraine could result in improved patient management, by targeted management of both migraines and the associated mental health disorders.

Under-ascertainment of migraine is often reported in literature as many patients with migraine do not seek medical attention. ${ }^{[3]}$ For that reason, some may argue that existing literature is presented in those with severe migraine only. However, substantial disability also occurs in a high proportion of patients with migraine who never consulted a physician (UK 60\%, USA 68\%), in those who never received a correct medical diagnosis (UK 64\%, USA 77\%) and in those who were only treated with over-the-counter medications (UK 72\%, USA 70\%). ${ }^{[3]}$

Associations between migraine and psychiatric conditions may be due to a bidirectional etiological effect, i.e., migraine causing psychiatric conditions which in turn worsen the migraine; especially migraine with depression, and panic disorder. ${ }^{[4]}$ However, the results obtained through cross-sectional analyses are extremely useful in understanding the burden associated with migraine and its comorbidities and in guiding public health policies and funding for health-care services. In the current issue, Ram Mohan et al. ${ }^{[5]}$ from a tertiary referral center from India, report the findings of their cross-sectional observational study. The study aimed to evaluate the prevalence of mood disorders in patients with migraine uncomplicated by other types of headache. The study also assessed the association between migraine related clinical features and comorbid mood disorders with implications on quality of life. The authors report that mood disorders are comorbid with migraine. Furthermore, mood disorders significantly contribute to migraine-associated disability. The authors suggest including questionnaires such as Hospital Anxiety and Depression Scale in screening all patients with migraine.

In addition to the findings reported by the authors in the current issue, a trend toward major depression being more common in females than males in the migraine group is often reported. However, this association is also statistically significant in the nonmigraineurs. ${ }^{[6]}$ Therefore, even though migraine and depression may be linked at a clinical level, sociodemographic factors also determine mental health.

Medication use - reportedly, antidepressant and antiepileptic drug use is highest in those with combined migraine and a mental health disorder, followed by those with a mental health disorder without migraine, those with migraine but no mental health conditions, and finally, those with neither condition. ${ }^{[5]}$ The only exception is tricyclic antidepressants which were used more in patients with migraines. Tricyclic agents are very commonly used for migraine prophylaxis; however, their use in the management of mood disorders, in particular, has declined over the years with the introduction of the selective serotonin reuptake inhibitors and selective norepinephrine reuptake inhibitors. ${ }^{[7]}$

Migraine and psychiatric comorbidities-health-related outcomes - patients with both migraine and a mental health disorder are more likely to have 2-week disability, restriction of activities, poorer quality-of-life compared with those with just one of the two conditions, and even more so than those with neither condition. ${ }^{[8]}$ Other studies which have examined health-related outcomes such as disability, restriction of activity, quality-of-life or mental healthcare utilization are restricted to migraine sufferers without taking into consideration associated psychiatric comorbidities. Edmeads et al. studied the impact of migraine on lifestyle, ${ }^{[9]}$ and reported that $85 \%$ of those with migraine reported substantial reductions in their ability to do household work and chores, $45 \%$ missed family social and leisure activities, and 32\% avoided making plans for fear of cancellation due to headaches.

In conclusion, although various theories have been suggested to explain the association between migraine and various psychiatric conditions, more studies are needed to elucidate the mechanism of this association and its impact on quality of life of patients.

Sita Jayalakshmi, Sudhindra Vooturi

Department of Neurology, Krishna Institute of Medical Sciences, Secunderabad, Telangana, India

Address for correspondence: Dr. Sita Jayalakshmi, Department of Neurology, Krishna Institute of Medical Sciences, Minister Road, 1-8-31/1, Secunderabad - 500 003, Telangana, India. E-mail: sita_js@hotmail.com 


\section{REFERENCES}

1. Ray BK, Paul N, Hazra A, Das S, Ghosal MK, Misra AK, et al. Prevalence, burden, and risk factors of migraine: A community-based study from Eastern India. Neurol India 2017;65:1280-8.

2. Lipton RB, Hamelsky SW, Kolodner KB, Steiner TJ, Stewart WF. Migraine, quality of life, and depression: A population-based case-control study. Neurology 2000;55:629-35.

3. Lipton RB, Scher AI, Steiner TJ, Bigal ME, Kolodner K, Liberman $\mathrm{JN}$, et al. Patterns of health care utilization for migraine in England and in the United States. Neurology 2003;60:441-8.

4. Breslau N, Schultz LR, Stewart WF, Lipton R, Welch KM. Headache types and panic disorder: Directionality and specificity. Neurology 2001;56:350-4.

5. Rammohan K, Mundayadan SM, Das S, Shaji CV. Migraine and mood disorders: Prevalence, clinical correlations, and disability. J Neurosci Rural Pract 2018;10:28-33.

6. Jette N, Patten S, Williams J, Becker W, Wiebe S. Comorbidity of migraine and psychiatric disorders - A national population-based study. Headache 2008;48:501-16.

7. Beck CA, Patten SB, Williams JV, Wang JL, Currie SR, Maxwell CJ, et al. Antidepressant utilization in Canada. Soc Psychiatry Psychiatr Epidemiol 2005;40:799-807.

8. Breslau N, Davis GC. Migraine, physical health and psychiatric disorder: A prospective epidemiologic study in young adults. J Psychiatr Res 1993;27:211-21.

9. Edmeads J, Findlay H, Tugwell P, Pryse-Phillips W, Nelson RF, Murray TJ, et al. Impact of migraine and tension-type headache on life-style, consulting behaviour, and medication use A Canadian population survey. Can J Neurol Sci 1993;20:131-7.

This is an open access journal, and articles are distributed under the terms of the Creative Commons Attribution-NonCommercial-ShareAlike 4.0 License, which allows others to remix, tweak, and build upon the work non-commercially, as long as appropriate credit is given and the new creations are licensed under the identical terms

\begin{tabular}{|l|l|}
\hline \multicolumn{2}{|c|}{ Access this article online } \\
\hline Quick Response Code: & Website: \\
\hline
\end{tabular}

How to cite this article: Jayalakshmi S, Vooturi S. Migraine and mood disorders: Prevalence, clinical correlations, and disability. J Neurosci Rural Pract 2019;10:1-2.

(C) 2018 Journal of Neurosciences in Rural Practice | Published by Wolters Kluwer - Medknow 